Philip Pettit*

\title{
Defending The Robust Demands of the Good
}

https://doi.org/10.1515/mopp-2018-1002

\section{Restating the claims}

The five commentaries on The Robust Demands of the Good (henceforth RDG) are incisive and constructive and I have learned much from thinking about them and trying to frame the individual responses offered later. But before looking at those contributions, it may be useful to restate the general position defended in the book, highlighting some claims addressed in the different commentaries.

Various goods of attachment, virtue and respect require, not just that you actually produce a certain effect, but that you would produce that effect under a range of counterfactual scenarios. The effect is exemplified by the care that you must provide if you give me love, the truth-telling you must display if I am to enjoy your honesty, and the restraint you must practice if you give me respect.

In order to give me your love, honesty or respect in any exchange, you must actually deliver that effect-that thin benefit-but you must also be disposed to deliver it robustly over any variations on the actual circumstances where, roughly, reasons of love or honesty or respect remain in place-the needs they satisfy remain pressing-and their effect is not disrupted. They will not be disrupted under two conditions. First, there are no considerations present to trump them. And, second, you remain capable of acting on those reasons: you are not hindered from exercising the capacity by some block or burden, and you are not stripped of the capacity by any psychological failing or malaise; there is no factor present that, by accepted criteria, would excuse the failure or exempt you altogether from being blamed.

It is a guiding assumption of the book that robustly demanding goods and the associated reasons are and should be central to human life. That normative assumption is spelled out on the first page:

In forming and maintaining special attachments, in proving faithful to the demands of virtue in dealing with one another, and in individually and communally sustaining a framework of reciprocal respect, we do incalculable, mutual good. We do a sort of good that is indispensable for our together enjoying a life that is truly worth living. (RDG, p. 1)

*Corresponding author: Philip Pettit, University Center for Human Values, Princeton University, Princeton, NJ, USA; School of Philosophy, Australian National University, Canberra, Australia, E-mail: ppettit@princeton.edu 
In the final chapter of the book, I repeat this assumption in similar terms, explaining that 'I take it as granted' that 'attachment, virtue and respect, suitably interpreted, are cast in our received, folk view both as agent-relative and agent-neutral goods' and that 'in casting them in this way, the received, folk view is fundamentally sound' (RDG, p. 204).

The aim of the book is not to provide a detailed analysis of any of the goods discussed and not to seek to explain why in general they are valuable: all it does in that respect, as noted later, is to try to explain why the goods involved require the robust as distinct from the expected provision of associated, thin benefits like care, truth-telling and restraint. The aim of the book, rather, is to identify the common, robustly demanding structure displayed by those goods-the first three chapters attempt to do this in turn for attachment, virtue and respect-and then to explore the significance of that structure for ethics in general: I do this in the final three chapters. Its significance, as the titles of those final chapters indicate, is to explain the close linkage between doing good and being good, to support a sort of priority for doing good over doing evil, and to raise an important issue for how the good should guide us in seeking to do right.

Dorothea Gädeke offers general thoughts about the relationship between the three sorts of robust goods identified, arguing for the primacy of the robust good of respect or, as she casts it, the robust right to respect. Federica Gregoratto addresses the robust good of love in particular and argues that the account presented can and should be extended to identify the pathologies to which romantic love is subject. And Isaac Taylor critically assesses my account of doing good and doing evil, questions the case it makes for seeing principles like the doctrine of double effect as fallible moral heuristics, and suggests an alternative way of supporting them.

The book has seven chapters, however, not just six. A middle chapter between the three on attachment, virtue and respect and the three on the significance of the robustly demanding character of those goods looks at what I describe as the rationale of robust demands. And this provides the main focus of attention for the commentaries by Benjamin Ferguson and Sven Nyholm. It may be useful to restate my claims in that chapter at greater length, since they are relevant in my response to both those commentators; the restatement highlights points not stressed in the book, benefitting from the stimulus provided by their papers.

The goods of attachment, virtue and respect are associated respectively with three types of relationship and they represent goods for the parties involved that answer to vulnerabilities that arise in the relationships. In relationships of attachment, we each need our partner to deliver the sort of benefit associated 
with our particular bond: the care of a lover, the favor of a friend. In our interactions as beings who rely on one another for various forms of supportnone of us is self-sufficient, after all-we need others to tell us the truth on certain topics, to live up to express or assumed commitments, and to help us out when we are in difficulty. Finally, in our relationships as agents, each with an autonomous capacity for choice, we need others to give us room to act in a certain domain-to anticipate, in the domain of the basic liberties-according to our own wishes: in any such choice, I will rely on you to 'respond to a conditional need on my part: a need, if I prefer $\mathrm{X}$ in an $\mathrm{X}-\mathrm{Y}$ choice, to enjoy noninterference with X-ing; and a need, if I prefer Y, to enjoy non-interference with Y-ing' (RDG, p. 78).

The robust goods of attachment, virtue and respect guard us against the vulnerabilities that arise in such relationships: the special vulnerability to a partner letting us down; the general vulnerability to others not telling the truth, not honoring commitments, not helping us out and so on; and the vulnerability to other agents who can deny us the space to act as we wish in the sphere of the basic liberties. While there is a common structure in the robustness of the demands made by these goods, they differ in various ways from one another. Thus, the good of respect is distinctive because it serves us as autonomous agents, not just as subjects in need of the special concern of partners or the general support of others. And goods of attachment like love and friendship are distinctive because they are relevant to relationships that we voluntarily enter, at least ideally, not relationships that are more or less inescapable in social life. ${ }^{1}$

While the book does not address the question of why robust goods like attachment, virtue and respect are valuable, there can scarcely be any reason to doubt that they are. This is because they generate benefits that we need to enjoy if we are to achieve the goals encoded in the corresponding relationships; the benefits answer respectively to our needs as voluntary partners, general dependents and autonomous agents. The goods are valuable, in other words, conditional on our being in such relationships. Consider, as a parallel, the fact that having another keep a promise to you is good but only conditional on its having been made. Just as the conditional good of having a promise kept does not imply that it is good that the promise was made, so the conditional good of respect or virtue or love does not argue for the good of enjoying the relationship on the existence of which its value is conditional. This observation is particularly relevant in the case of a voluntary relationship like love. While your love may reduce my vulnerability to you as my partner, it does not follow that I value the

1 An exception may be my dependence on you insofar as I rely on you as an interlocutor or insofar as I rely on a commitment or promise you made. 
relationship itself for the way it reduces overall vulnerability; far from reducing such vulnerability, it may increase it.

When I enjoy any robustly demanding good, however-say the good of your love or honesty or respect-I do not merely gain access to the benefit of your care or truth-telling or restraint, I gain robust or secure access to the benefit. And that raises the problem addressed in the chapter on the rationale of robust demands.

In cherishing the love or honesty or respect that you give me here and now, I rejoice, not just in the fact that you actually give me the associated care or truthtelling or restraint, nor just in the fact that you would give it to me in certain likely variations on current circumstances. I rejoice in the fact that you would give me care or truth-telling or restraint of the relevant kind even in extremely improbable scenarios: you would give me the care of a lover, for example, in variations where, like Jack in Oscar Wilde's comedy, I am called by a name you dislike. Thus, in cherishing your love or honesty or respect, I display the same concern for enjoying your care or truth-telling or restraint in scenarios that are extremely unlikely and in scenarios that are highly probable.

'Why should our interest in achieving the benefit remain unchanged across relatively probable and relatively improbable scenarios?' (RDG, p. 110). Why should we display a concern with securing the benefit in a way that involves 'probabilistic insensitivity' (RDG, p. 109)? That is the question raised in chapter 4.

The answer provided involves two claims. First, that it makes sense to cherish a disposition like that which is associated with your love or honesty or respect for the fact that it secures such benefits as distinct from making them more probable: this, because security in certain contexts is more important than probability. And, second, that when we do this we cherish the disposition in itself or, strictly, your acting out of it: we cherish the disposition, not for a contingent effect it happens to have, but for a property that it must by its nature possess.

Why does it make sense to cherish security rather than probability in regard to certain benefits? We cherish making benefits probable-maximizing their expected realization-in any context where they are subject to involuntary contingencies like those that nature imposes on us: that is why we are happy to be vaccinated against one or another virus. But we cherish making benefits secure-that is, available across various relevant scenarios, probable and improbable-where the contingencies that determine which scenario materializes are under the voluntary control of another; that is why we are happy to be protected by the law, even when others are perfectly good-willed towards us. To make a benefit secure in this way is to protect ourselves against the vagaries of the other's will: against their weakness or akrasia, against the influence of whim or caprice or impulse, against the emergence of hostile feelings, or against a wish on their part to exercise power over us. 
Dangers of that kind are always possible as a result of exposure to others in our relationships as voluntary partners, general dependents and autonomous agents. But whether they are likely or unlikely to materialize in a relationship, the presence of a disposition like love or honesty or respect should help to soften or block their impact. If the other in such a relationship acts out of love or honesty or respect, then they will adopt a deliberative perspective that more or less rules out the sort of calculation that might trigger the danger. Thus, the disposition should help to guard against the danger, not insofar as it is likely to materialize in actual circumstances-it may not be-but insofar as it may be triggered by the other's free will. Thus, there may be no ground for seeking to reduce the probability of my lover going off me because I change jobs or gain weight: that may be very unlikely already. But there may be ground for welcoming the fact that the lover's disposition, as I assume, makes the consideration of my job or weight irrelevant to the relationship.

This is to say that it makes good sense to cherish a disposition like love or honesty or respect for the fact that it secures me against the waywardness of another's will, even though such security involves a probabilistic insensitivity. But, turning to the second element in the position adopted, this implies in turn that when I cherish such a disposition under its securing or protective aspect, I value it in itself: I value your acting out of the disposition for a property that it essentially has and not for any contingent effect that would make it beneficial and welcome.

That property is essential to each of the dispositions we are considering; it would be a different disposition, or not a disposition at all, if it failed to constitute or at least approximate that guarantee. Hence in cherishing any such disposition in you, I cherish it for what it is necessarily- what it is in itself- and not for an effect it happens contingently to have. (RDG, p. 109)

With these points in place, I turn finally to a consideration of the five individual commentaries provided. Taking them in turn will help to guard against losing sight of the distinctive contribution of each. I consider the commentaries in the alphabetical order of the contributor surnames.

\section{Benjamin Ferguson}

Benjamin Ferguson's paper raises a host of questions on which he makes various interesting and often congenial observations. But he misconstrues my argument about the rationale of robust demands and that leads him to misread 
many of the things I say. That's the bad news. The good news is that while those mistakes lead him to think that his own final view is sharply opposed to mine, it is actually very close to that which I embrace.

Ferguson takes The Robust Demands of the Good, in particular the argument in chapter 4, to offer an explanation of why we human beings cherish robustly demanding goods of attachment, virtue and respect and why we cherish people's responsiveness to corresponding reasons. I certainly do make an assumption about 'the manifest appeal of attachment, virtue, and respect' (RDG, p. 197). But I do not conceive of the argument in chapter 4 about the rationale of robust goods as an attempt to support that assumption. As stressed, I see it only as an attempt to resolve a puzzling aspect of the way in which those goods appear to be valuable: viz., the probabilistic insensitivity that a concern with the goods gives us in relation to corresponding benefits like care and truth-telling and restraint.

If I enjoy the robust good of your love or honesty or respect, then your disposition secures or protects me in some measure against changes of mind on your part. Respectful dispositions should ideally be constrained by law, on my view, whereas other dispositions should not be so constrained: by their very nature they are 'discretionary', in the sense that you are free to drop them with impunity (RDG, p. 134). But even unconstrained dispositions will impose a 'deliberative perspective' on you that will guard to a considerable extent against your thinking like a fair-weather rather than a real friend, for example, or an opportunistic truth-teller rather than an honest broker (RDG, p. 127). That perspective will rule out your thinking in a calculating, self-regarding way about how to act; it will put various options off the menu of possibilities that you consider.

Thus, for as long as you deliberate about how to act from within such a perspective-and, of course, the perspective may be more or less stable over time-we will enjoy more security about the treatment we are likely to receive at your hands; we will not be hostage in the same way to whatever incentives or impulses, weakness or hostility, might happen to assail you in that exchange. Moreover, because such dispositions are likely to support and be supported by social norms-fully internalized, public norms, as I describe them (RDG, p. 39)their protective effect will be buttressed by the penalties of disesteem that you will face if you breach such norms.

The book is not sufficiently clear about the fact that I do not offer a reason for cherishing robustly demanding goods, only a rationale for why the demands that those goods make are probabilistically insensitive. And that is why Ferguson mistakes many of my claims.

The misunderstanding is compounded by the fact that he treats my proposal as a claim that people are strategically motivated when they cherish or seek dispositions of friendship or honesty or respect in others. I claim, as he says in the abstract 
of his paper (Ferguson 2018, p. 9), 'that we value the robustness of these goods because it diminishes our vulnerability to others'. I actually think that we generally cherish such goods for their own sake-as I put it in the book, for what they are in themselves-and that while the security they provide helps explain why they are attractive to us, they do not do so in the manner of a strategically sought, independent reward. More on this issue in replying to Nyholm.

Ferguson's strategic reading of my claims is particularly salient when he claims that my argument in the case of love is dramatically undermined by two facts, first, that we may not value the love of someone, despite the fact that it reduces our vulnerability to them; and second, that a desire to reduce vulnerability cannot explain why we value loving others as well as being loved by them. The facts are both indisputable but equally they are both irrelevant to my claims.

I am happy to acknowledge, for example, that entering a loving relationship may increase our vulnerability overall, making us dependent in new ways on the care of the other. Presumably we enter such a relationship for independent reasons: we fall in love and this increases our overall vulnerability, leading us to renounce stoic self-sufficiency. But it is consistent with acknowledging this increase in overall vulnerability to hold that depending on the care of the beloved is much less hazardous in the presence of a loving disposition on their part than it would be in its absence; the disposition assures us that our beloved will not calculate in every relevant case about whether they can do better for themselves, or better overall, by withholding the care.

So much for clarifying matters on which I should have been clearer, guarding against the misunderstanding and misinterpretation discussed. But our discussion has a positive as well as a negative bearing, for it enables me, finally, to show that Ferguson's own view, defended towards the end of his commentary, converges with mine.

Borrowing an idea introduced in the book, Ferguson observes that when we describe what you do as a loving action we offer a disposition-dependent, or motive-dependent, characterization of it, and when we describe it as an act of giving care we describe it in disposition-independent terms. And then he argues that you will provide me with love when you are disposed or motivated to perform loving actions, friendship when you are disposed to perform friendly actions, in suitable worlds. The idea guiding the approach is presented as maximizing or promotional in character rather than focused on security: 'what is being maximized', he says in the case of attachment, 'are acts of love or friendship, not mere care or favor' (Ferguson 2018, p. 26). ${ }^{2}$

2 In these worlds, reasons of love are present and undisrupted, or at least undisrupted by trumping considerations: this, because Ferguson has some worries about my conception of 
But this view converges on my own. How do you maximize the acts of love or friendship that you perform? By maximizing the occasions when you act out of a corresponding disposition or motive. And how do you do that? By ensuring for each of those occasions that you act out of the appropriate disposition: you provide the care or favor in expression of the appropriate disposition and not, for example, out of personal opportunism or even general benevolence. But that means that on each of those occasions you provide the care or favor robustly over variations on the circumstances that preserve the relevant reasons of love or friendship and do not introduce disrupting factors.

My focus in The Robust Demands of the Good is on particular actions of providing love or friendship, or indeed honesty or respect, and my claim is that in order to provide such a good on a given occasion you must confer a corresponding, thin benefit-care or truth-telling or restraint-and you must do so robustly over a range of possible variations on features of the occasion, acting out of a suitable disposition. While I do not ask about what measures you should take over your life as a whole, my commitment to consequentialism leads me to hold that, other things being equal, you should promote those acts as much as possible: you should maximize the expectation of providing suitably robust care and truth-telling and restraint. That is why I argue in the book that to emphasize the robust provision that giving love or honesty or respect requires on any occasion-this, despite the probabilistic insensitivity involved-is not to give up on probability and not 'to abandon an expectational framework' (RDG, p. 136). Thus, the viewpoint presented in the final part of Ferguson's paper is one that I can fully endorse.

I have tried to explain my view more clearly and to show that it actually converges with Ferguson's own. While it would be nice to end on a wholly ecumenical note, it is worth nothing for the record that other differences divide us. Thus, as the presentation of my view above may indicate, I stand by the following claims, contrary to things he says or suggests. First, that it is reasonable to link the cost of breaching an associated norm with the cost of not acting on a purported disposition: the association supports the link. Second, that security over what may happen in scenarios that are possible at a time, relative to a particular exchange, does not strictly require security over future scenarios: the securing disposition may not be very stable. Third, that providing extra security against certain changes of attitude does not require protecting in any

excusing and exempting conditions, which I address briefly in the concluding paragraph below. He does not think that all such worlds need be relevant, only 'a sufficient number', where sufficiency is left for specification in local culture. But this difference need not concern us since, as he mentions, it is in line with a concession I explicitly make in the book (RDG, p. 26). 
absolute sense against them: it may just involve increasing the protection. And fourth, that a disposition does not disappear, triggering exemption, when the opportunity for exercising it vanishes: a gold-digger retains a disposition to sponge on me, even when I cease to be wealthy.

\section{Dorothea Gädeke}

Dorothea Gädeke and I agree on many issues and it may be useful to rehearse the agreement before exploring the differences. Her paper is fundamentally congenial from my perspective and I am grateful for the illumination it provides: she uncovers aspects of the topics we each address that I had not previously registered.

We both agree that there is a structure common to the goods that are associated, for example, with having attachments like love and friendship, virtues like honesty, fidelity and kindness; that this consists in the fact that those goods make robust, not merely contingent, demands on how we behave; and that we satisfy those demands as a result of acting out of corresponding dispositions. We both agree that those dispositions and the goods they enable us to provide 'are of value in and of themselves', despite the fact that they have that value-although, I would insist, only in part-'because they protect us against the will of others' (Gädeke 2018, p. 31). And we both agree, finally, that the structure displayed by goods of attachment and virtue is replicated in a certain way by the good of respect that we enjoy at one another's hands.

We both also agree that respect is different from other robustly demanding goods in a number of ways. We agree that there is only one such good involved in this category, where there are many goods of attachment and virtue, although I would add that respect takes different forms in relation to different activities like speech and association and movement, and so on. We agree that respect requires on any suitable occasion, not just that you should act out of a disposition of respect towards me, but that you should be constrained by law to do so. We also agree that it will mean little or nothing for you to respect me if you do not give me equal respect with others; at least not in the sense of respect used in the book. ${ }^{3}$ And in view of that connection with equality, we each presumably

3 Neither of us distinguishes between the requirement that you should give everyone equal respect-this, presumably, because the same considerations apply with regard to each-and the requirement that you should give everyone respect as equals. In this latter case you respect me, not just because of lower-order considerations that happen to apply equally with others, but because of the higher-order consideration that I am equal to others in those first-order regards. 
agree that respect can materialize only in the presence of a common understanding-presumably, encoded in law-as to the range of activities in the pursuit of which I can demand equal respect from you. The range in question is that which Kant describes as the range of external freedom in The Discourse on Right; I cast them as the basic liberties recognized in a society.

Differences appear between Gädeke and me, however, on the issue of the sort of action respect requires you to display and on the explanation of why that treatment needs to materialize under legal constraint, not just on a dispositional basis. I will address these in turn, mainly in a conciliatory mode, and then identify a question where we may have a deeper disagreement.

What form of behavior is required for you to treat me respectfully? In The Robust Demands of the Good I take it to consist in your restraining yourself from not interfering with me in the exercise of the basic liberties, where interference is taken to include removing an option, replacing an option with a penalized alternative and misrepresenting the options to me (RDG, p. 78). But Gädeke points out that this is a different approach from that taken in earlier work, such as in my 2001 book, A Theory of Freedom, where I emphasize the connection between your respecting me and your addressing me discursively: your treating me as a giver and taker of reasons that we can each endorse, rather than as someone to push around or penalize, threaten or stand over, deceive or manipulate. And she argues for equating the behavior required for respectful treatment with discursive address.

I am happy to go along with this equation, with one qualification already noted in the earlier book. Gädeke says that 'when others fail to display the disposition to engage discursively, I do not enjoy ... respect in the full sense' (2018, p. 42). It may be that I do not enjoy your active respect, as we might put it, when you do anything other than engage with me discursively. But there is a passive sense in which I can enjoy your respect in the absence of such engagement. This may happen, for example, in cases where you just hang out with me, join me in climbing a mountain, even cajole or tease me or, because we don't know one another, don't have any dealings at all with me. I will enjoy your respect in such a case to the extent that your behavior is compatible-robustly compatible-with adopting discursive address at any point. You respect me passively or virtually, not actively, insofar as you would resort robustly to discursive address, or to some cousin of address, if an occasion arose where you wanted to influence me and the resort to address was a feasible option.

Gädeke would probably agree with this qualification and I mention it only for completeness. But why opt in this book for equating your showing me respect with your robustly avoiding interference in the space of my basic 
liberties rather than with your treating me in that space in a robustly discoursecompatible way? My response is not that I changed my mind on this issue but rather that I decided it was simpler to prioritize non-interference in a book devoted to identifying a common structure between goods of attachment, virtue and respect. As love requires robust care and honesty robust truth-telling, it was simpler to be able to say that respect requires robust non-interference-robust restraint-rather than the pursuit of robustly discourse-compatible treatment. And although this line is simpler, it is not deeply misleading. For the treatment required by respect involves an absence of interference in most ordinary cases. The only cases where it does not are those where you show a lack of respect by having nothing to do with me or in cases where you treat me as beneath contempt: beyond the reach of exhortation, censure or redemption.

Still, it may well be that I would have done better to stick with a focus on discursive address rather than non-interference, and Gädeke directs us to some reasons why that may be so. One that is implicit in her discussion is that the reference to discursive address helps to explain why respect is so valued amongst us. Its value consists in the fact that it enables us to interact with one another in a discursive or deliberative manner; to make up our own minds on issues raised in the exchange without any element of force or deception, and to build up relationships and community.

Gädeke explicitly mentions two other reasons why it might have been better to retain the connection between respect and discursive address. One is that it helps to explain why respect requires, not just that we should each be disposed to treat one another respectfully, but also that we should be constrained by law to do so. She stresses, citing my earlier book, that discursive address becomes elusive if one of us manifestly has a power of interference with the basic liberties of the other, which they may exercise as they wish: if the more powerful person is not constrained to behave respectfully. And a further reason is that if respect is associated with robustly discourse-compatible treatment, and freedom-in the republican sense-with robust non-interference, then it is clear why respect requires us to be independently disposed as well as legally constrained to treat one another respectfully, whereas freedom does not strictly require this; however empirically unlikely, we might enjoy robust non-interference even if each of us resented not being able to interfere with others.

Apart from making points of these kinds, which I am happy to concede, there is another very useful and welcome point that Gädeke makes; it fits with my own views, although I certainly failed to register it in the book. This is that if respect is a more basic good than goods of attachment and virtue, as it plausibly is, then the demands of respect can help to identify the range of scenarios over which goods of attachment or virtue are allowed to make demands. Thus, if your 
love for me does not impose slavish demands on you, as I maintain (RDG, p. 138), that may be because it would then be inconsistent with my respecting you, as it will certainly be inconsistent with your self-respect. And if your love does not require you to show me care in a situation where that would put another's life at risk, and introduce a trumping consideration, that may be because it would be inconsistent with your respecting that other person.

Finally, to a difference between us. Gädeke thinks that the best way of registering the basic role of respect is to say that there is a right to respect that is fundamental and that constrains the goals we may seek to pursue: not just our self-interested goals but also the goals of instantiating or promoting various attachments and virtues. 'The robust demands of the good', as she puts it, 'are only robust within the confines of what respect requires' (2018, p. 44). The robust demands of respect are 'robust demands of the right, not of the good' (2018, p. 30).

I prefer to ground my ethical and political theory in an account of the neutral good-that is, on a consequentialist basis-rather than in the postulation of any deontological right, even a right to respect (see Pettit 2018a). But Gädeke suggests that I can treat the right to respect as deriving from a practice that is not just valuable but inescapable, as I argue in the earlier book. This, of course, is the practice of discursive exchange in which we give and take reasons. The manifest value and inescapability of that practice ought to make it into a 'default option' in dealing with one another, providing the most basic support possible, at least in a consequentialist view of morality, for abiding by its requirements and recognizing the rights it gives us: at the most abstract level, our right to respect.

Thus far I happily go along. But I demur at one final observation she supports, or at least seems to support, when she says that respect 'delimits what others may do to me, even in the pursuit of the good' (Gädeke 2018, p. 45). If she means that there are absolutely no circumstances where the good could require the suspension of respect, then she must be treating the right to respect as an absolute right, a position that would require a deontological perspective. I would say the cause of the good-say, to go to the very extreme, the cause of preserving life on earth-might argue in certain circumstances for the suspension of respect; it would do so, for example, if only disrespectful actions could save life on earth. Gädeke might admit this by denying that the deontological right to respect is absolute, in which case she would need to provide an account of the conditions under which the right does not apply. Or she might join me in treating respect as a good that is grounded in our very nature and practice as discursive beings but that, nonetheless, is not proof against every possible trumping consideration. 


\section{Federica Gregoratto}

Federica Gregoratto's essay is developed in interaction with my claims in The Robust Demands of the Good-and in other works-but constitutes an independent, valuable contribution to a debate on which I say embarrassingly little in the book. That debate revolves around the all too salient possibility that the attachment involved in romantic love, whatever good it may seem to promise in the abstract, may become a source of evil in its concrete manifestations. This is the possibility, in particular, that women in heterosexual relationships may be systematically exposed-that is, exposed for reasons that recur in many different circumstances-to the domination of their lovers.

One person suffers domination at the hands of another, in the sense at issue here, to the extent that in the realm of the basic liberties, as discussed in the reply to Gädeke, the other is capable of interfering in their choices. Thus, a woman will be dominated by her male partner to the extent that he has such a power, being able to interfere with relative impunity in her exercise of the basic liberties: being able to interfere in those choices, for example, without personal difficulty, legal cost or even social embarrassment. The woman will be dominated in this way, and will not enjoy proper freedom as a person-or in my sense proper respect-even if her partner is devoted to her and allows the greatest possible latitude of choice. In that case she will be able to choose as she wishes but only because he wishes her to be able to choose as she wishes: in effect, only because he permits her to do so. And that means that she is subject to his will in domains where she clearly should not be.

Looking for a dramatic example of this scenario in one of my recent books, Just Freedom (2014), I cited the relationship of Nora and Torvald in Ibsen's play, A Doll's House. Torvald does not even wish to dominate Nora, as I imagine that scenario, but the legal power he enjoys over her in the world depicted is such that whether he likes it or not, he does dominate. It is only by his permission, by his grace and favor, that she can read the books that appeal to her, for example, wear whatever clothes she wishes, speak or write on any topic that engages her, or associate with friends of her choosing.

Gregoratto suggests that romantic love, as it has been generally conceptualized and governed by social norms, contains the seeds of domination, even when the legal situation is not as bad as in the world portrayed by Ibsen. She broadly endorses the claim that to give someone love, the lover has to provide care for the beloved, not just contingently on the here and now-not just contingently on this being congenial or convenient-but robustly across 
variations on the here and now where reasons of love remain relevant and are not eclipsed by trumping considerations or hindered by excusing or exempting conditions. And she also goes along with the idea that this abstract structure can be interpreted by different individuals or cultures in different concrete forms, as different criteria are introduced to determine what are reasons for love, what are trumping considerations, and what are plausible excusing or exempting conditions (Gregoratto 2018, p. 56). But she sees a permanent possibility for domination in the fact that it is always possible for a caregiver to exploit the other's need for care-'be sweet or I will withdraw my care'-or for a care-recipient to exploit the other's desire for reciprocation: 'be sweet or I won't reciprocate' (Gregoratto 2018, p. 54).

She looks at this possibility of domination in particular under the hypothesis that 'women are, or appear to be, more in need of love'. In that case, she suggests, 'their attachments put them in a position of dangerous dependence on men, even when it comes to romantic commitments' (Gregoratto 2018, p. 55).

When writing on this possibility in other works-I barely touch on it in RDG-I have concentrated on the need for the law to guard against the domination of women by giving them the same social and political rights as men, by providing for sanctions against domestic abuse, by providing for access to divorce and to appropriate divorce settlements, and by fostering and perhaps financing (at arm's length) the development of support structures and of refuges for women fleeing abusive relationships. Such initiatives might be expected to help promote women's republican freedom: that is, their freedom as nondomination. Gregoratto, as I read her, is happy to support such measures but she argues, persuasively, that more is needed at both the individual and institutional level.

She suggests that more is needed at the individual level when she says that for 'the kind of freedom that is at stake in romantic relationships, Pettit's notion of republican freedom must be combined with a positive conception of freedom (freedom as self-determination)' (Gregoratto 2018, p. 64). I agree, because of believing that where freedom as non-domination may require the empowerment and protection of a suitably democratic rule of law, such legal security is consistent with personal failures of self-determination that may continue to expose an individual to the power of others. Someone adequately secured by the law-secured to the point, as I have put elsewhere, of being able to look others in the eye without reason for fear or deference-may not be self-determining enough to overcome their fear or deference. And this may be so, to anticipate, even if the norms of the society support the law, ensuring in the fullest way possible that the person can look others in the eye without reason for fear or deference. Because of a slavish desire to please other people, for 
example, they may expose themselves to exploitation and domination by those who perceive this weakness.

This is to say that more is needed at the individual level, over and beyond the basic institutional measures mentioned, to ensure women's freedom in romantic relationships. But Gregoratto insists, and I strongly agree, that more is needed also at the institutional level. This is mainly because of the structural domination, as I have called it elsewhere, that social norms, in particular gendered norms, may introduce; structural domination is closely connected with what she describes here, in Michael Thompson's phrase, as extractive and constitutive domination. People will be structurally dominated by social norms, as they may be structurally dominated by any patterns in the organization of society, insofar as the presence of those norms makes it possible or likely that they will be dominated-dominated, in the more basic sense of the term-by other individuals or groups of individuals or, indeed, by the state itself.

A social norm, by the account offered in the book (RDG, p. 37), is a social regularity such that, first, almost everyone conforms to it, second almost everyone expects others to approve of conformity and disapprove of non-conformity, and third, this expectation helps to support general conformity, where all of this is a matter of more or less common awareness. Such a norm may or may not be internalized. It will be internalized when there is general approval of conformity, and not otherwise: not, for example, when, like students in the drinking club described in the book, people are mistaken to think that they will lose the esteem of their peers if they fail to conform to the regularity; if, in the student case, they drink less than a certain amount. A norm that disadvantages one group in relation to others will facilitate domination most deeply if it is internalized by the disadvantaged, since it will make them spontaneously compliant. But whether or not it is internalized, the norm will facilitate domination by shaping the expectations and behavior of both the advantaged and disadvantaged.

Whether internalized or not, it is manifest that there are norms in most of our societies for how women and men should behave and that these give an asymmetric degree of power to men over women in romantic relationships. Gregoratto illustrates the possibility by looking at how such norms might lead an academic couple, Albert and Beth, along different career paths, especially after the birth of children. The norms envisaged would require a mother to devote herself more than a father to the nurture and welfare of the children and would lead Beth away from academic priorities, creating a situation in which it is Albert who thrives.

How to deal at an institutional or at least social level with this sort of problem? How to achieve the reciprocity that we must all aspire to and that 
The Robust Demands of the Good is too glib in assuming? How to ensure that when they enter and maintain romantic relationships, as I have put it elsewhere, 'men and women' should do so 'from positions of relatively equal strength'?"

Gregoratto's proposal, as I read her comments, is that we must reconceive the sorts of demands that romantic love makes and cultivate ungendered, undominating norms in our own thinking and that of our fellows. Such norms would preserve the abstract, robustly demanding structure of love but offer interpretations that are likely to guard against the danger of domination. Thus, while recognizing the need for further conceptual and empirical research in the area, she calls for recognizing that lovers should 'be able to deal with disagreement, ambiguity and conflict constructively', even to the point of rejecting 'certain demands of care'. As she goes on to say, 'love must be viewed as an agonistic process, as something that is more conflictual than Pettit acknowledges' (Gregoratto 2018, p. 62). I find this suggestion plausible, freely admitting that I do not sufficiently probe this aspect of love in the book.

\section{Sven Nyholm}

Like Benjamin Ferguson, Sven Nyholm treats my discussion of the rationale of robust demands as an attempt to explain why robustly demanding goods in general are valuable. And he takes the security-based rationale cited in chapter 4 as a goal such that pursuing any one of those goods is supposed to be appealing just insofar as it happens to represent a means of achieving an overall, inherently desirable form of security. The fact that he and Ferguson both misunderstand the role of the chapter, misinterpreting the sense of rationale that I employ there, clearly shows that the responsibility for the misreading lies with me. I should have gone out of my way to guard against what I can now see is a perfectly excusable construal of my aims.

While acknowledging that the construal is excusable, of course, I do want to emphasize that it does not answer to my intentions, however inadequately they were conveyed. As I mentioned in discussing Ferguson's commentary, the chapter on the rationale of robust demands explains at the very beginning that the issue addressed is why, in cherishing robustly demanding goods, we should be unresponsive to certain probabilistic facts. The issue is why in

4 In Pettit (2014, p. 61). 
cherishing your love or honesty or respect, we should display the same concern for enjoying the corresponding benefit-care or truth-telling or restraint-in probable and improbable scenarios: why we should in that sense display a sort of 'probabilistic insensitivity' (RDG, p. 109).

The reason or rationale for the insensitivity, to repeat the crucial point, is that as we care in some contexts about making good things more probable, so we care in others-particularly, in the context of social relationships-about making them more secure: that is, more secure against the vagaries of the human will. But the idea is not that we maintain suitable relationships, and look for the enjoyment of corresponding robustly demanding goods, because we expect that doing so will increase our overall security, reducing our vulnerability to other people. My point is that once we are in a relevant relationship, we depend on the care or truth-telling or restraint of others; the relationship will serve us badly if that sort of benefit is not available. That means that once we are in a relevant relationship, the reduction of vulnerability provided by love or honesty or respect is bound to matter greatly. But it does not mean that we maintain or enter the relationship in order to reduce our vulnerability overall. The analogy with promise-keeping should make the point clearly.

Nyholm concentrates almost entirely on the case of romantic love, taking me to hold that 'the primary reason to value love is that it serves as a means to the protected and secured possession of certain other goods' (Nyholm 2018, p. 95). Love is 'primarily valuable as a means to other ends, such as the protection from harms and ills, or the stable provision of "care"' (Nyholm 2018, p. 95). In stressing that a disposition of love-strictly, acting out of a disposition of love-is meant on my account to promote other goods as a means, Nyholm takes that disposition to relate contingently or imperfectly to those other goods; its presence does not entail their presence. And insofar as he takes those other goods to include protection from harms and ills-benefits that other dispositions can promote as well-he takes the disposition to be a dispensable means of promoting the valued ends, not just a means of a contingent sort.

There are three aspects of this reading that jar with me. One is that it makes love out to be a means of achieving quite independent benefits. A second is that it presents love as a contingent or imperfect means of achieving them. And a third is that it depicts it as a dispensable means.

For reasons elaborated earlier, love does not serve as means to an independent benefit; the good for me of its associated effect-robust care-is conditional on my being already in an intimate relationship. There is a sense in which it serves within an intimate relationship as a means and so I refer to it in the heading of a sub-section 'as a means of securing or protecting thin benefits' 
(RDG, p. 120); this heading is meant to contrast with the headings to earlier sub-sections in which I criticize rival views that treat it as a means of promoting certain effects rather than securing them. But if love is a means of securing a thin benefit like care within an intimate relationship, it is neither a contingent nor a dispensable means.

Take the contingency issue first. We sometimes describe a factor whose presence necessarily entails that this or that is the case as a means of making it the case. ${ }^{5}$ Thus, the presence of suitable anti-bodies in your blood may be described as the means that makes you immune to a certain disease, although the immunity is not a contingent or causal effect. Let suitable anti-bodies be present and the immunity will follow automatically and without the temporal lapse that a causal connection would require; the anti-bodies constitute the immunity, as we say, entailing that you are immune, rather than causing the immunity or bringing it about in any other contingent manner. In the same way, the fact that you act out of a suitably loving disposition towards me entails that you give me robust care, rather than bringing it about in a causal or otherwise contingent way. It is a constitutive, non-contingent means of delivering that effect.

As acting out of love is a non-contingent means of securing care within an intimate relationship, it is also an indispensable means-the only possible means-of achieving that effect. You will care for me to the extent that you 'register and respond to the stimulus of my needs and wishes in the partisan manner we expect of a lover' (RDG, p. 12). And you will be suitably disposed to provide such care robustly just insofar as you are disposed to provide it in all scenarios where reasons of love obtain and are not disrupted by trumping considerations or excusing or exempting factors. But that means that no substitute disposition like a spontaneous inclination or a feeling of pressure could do the work done by the disposition of love, since it would deliver care only so long as the inclination or pressure remained in place. And that would not be good enough: 'if you love me then it must be the case that you provide me with care even under some scenarios where you are not inclined, or not pressured, to provide it' (RDG, p. 24).

These remarks are designed to emphasize how far I shrink from the picture that Nyholm, and indeed Ferguson, read into what I say about robustly demanding goods, and love in particular. On their reading, I hold a view about love that represents it as an 'imperfect, ideally dispensable means of maximizing the expectation of associated benefits' (RDG, p. 136). This is a sort

5 For a discussion of the different factors that may be treated as means in this broad sense, see my paper (2018b) which elaborates some implications of the book under discussion here. 
of view of which I say that it is 'counter-intuitive to the point of extreme cynicism' (RDG, p. 114).

The picture Nyholm ascribes to me is particularly unattractive in the case of love, for this relationship, as mentioned earlier, is one that we enter voluntarily, at least in the ideal case. If I value your disposition of love as a contingent, dispensable means of achieving some other goods-in Nyholm's phrase, 'the protection from harms and ills, or the stable provision of "care"' (2018, p. 11)then presumably it is with that independent payoff in mind that I will seek to win your love. And that really is counter-intuitive to the point of extreme cynicism.

While I concede that I bear responsibility for the payoff-centred reading of the view I develop in chapter 4, there is another aspect of Nyholm's construal that I find more puzzling. Drawing on the analogy with my account of freedom as requiring robust non-interference, he argues that my account of love represents it as having only negative as well as only contingent value. This I find puzzling, since the robust care with which I associate love is surely something positive.

Nyholm appears to overlook the positive character of care, in arguing that I present love as a negative good insofar as 'it protects us against our lovers' potentially making unexpected choices that would be hurtful to us' (2018, p. 93). And as against that claim, he argues that 'there are various things about love itself that we positively want to have present within our lives' (2018, p. 95).

I endorse that positive view of love as I endorse his claim, as against the view he ascribes to me, that 'love is typically and better regarded as an end in itself, or a good on its own account' (2018, p. 96). More generally, I endorse much of what he says in the second part of his paper, which goes through features of love that he takes me to neglect. This is a valuable contribution to the philosophical discussion of love, underlining the fact, which he allows that I myself can acknowledge, that love 'encompasses many more things than solely the robust disposition' to provide care (2018, p. 91).

In concluding his piece, Nyholm says that it is 'nice to have secure access to the actions that constitute our lovers' care' (2018, p. 99), suggesting generously-perhaps over-generously in view of his construal-that my account, 'strictly speaking', does not contain 'false or incorrect propositions about love and its distinctive kind of value for us' (2018, p. 101). I am happy to concede in return that despite the aim of the book in identifying the robustly demanding structure of various goods, my account neglects the interesting sorts of points he makes, and that it would have been good, as he suggests, to temper 'its search for general patterns with due sensitivity to how the values that are being linked together based on their more abstract features may also differ from each other in important ways' (2018, p. 90). 


\section{Isaac Taylor}

Isaac Taylor challenges a number of positions that I adopt in the discussion of doing good and doing evil. Before examining his claims it may be useful to summarize briefly the position I take. While robustly demanding goods like love, honesty and respect bulk large in social life, robustly demanding evils do not. If they are to correspond fully to robustly demanding goods, then robustly demanding evils would require a person, not just to impose a certain cost on others, but to do so even across scenarios where that would run against the agent's independent interest or inclination.

We should not expect such fully robust evils to be as important on the negative side of the moral ledger, as we expect their counterparts to be important on the positive. Social relationships of the kind reviewed in my restatement of the book's claims require you to overcome self-interest in living up to standards like those of love, honesty and restraint, meeting their robust demands. But there is nothing of the same kind that requires you to live up to standards of evil, meeting correspondingly robust demands; there are no standards of evil as such.

Where doing evil in the normal case just involves giving into self-interest and failing to do good, doing evil in the sense of doing robustly demanding bad would require the fanatical psychology associated with consuming envy or hatred or the like. I call evil of the first sort 'mundane maleficence', evil of the second sort 'heroic maleficence' (RDG, p. 176). There is an asymmetry between doing good and doing evil insofar as heroic maleficence-the counterpart of the robust beneficence of love, honesty and respect-is extremely rare. Although I do not argue that point, I now incline to think that it may even be incoherent, requiring an agent to seek to do another bad, without seeing any distinct benefit or value in the treatment.

While an asymmetry holds in this regard between doing good and doing bad, however, the book argues for symmetry in another. The symmetry appears between the sort of beneficence that falls short of satisfying the standards of robust goods-mundane beneficence, as we might call it-and mundane maleficence. If it is good to give me care or truth-telling or restraint with the full robustness associated with love or honesty or respect, then presumably it is better to give me that benefit more rather than less robustly, even if you do not reach the threshold of full robustness. And I suggest that a parallel holds on the side of evil: that it is worse to display a more rather than a less robust form of mundane maleficence. The independent argument offered here is that maleficence is always associated with imposing a cost and as it becomes more robust 
'there are fewer constraints on when you would be prepared to impose that cost on me' (RDG, p. 176). With fewer constraints in place, then, I will be more exposed and vulnerable to your will: the more robustly the evil is imposed, the worse it is.

Taylor argues against this more-robust-the-worse principle. Indeed, he maintains the contrary view that as my vulnerability to your will decreases insofar as you have the dispositions associated with more robustly provided benefits, so my vulnerability to your will must also decrease with more robustly imposed costs. He holds that 'when people produce more robust harms, their will is actually more constrained than when they produce less robust ones' (Taylor 2018, p. 73).

Taylor supports this thesis with an appeal to intuitions about some imagined cases that I find less than convincing. But he also gestures at an abstract argument, based on what doing more and more robustly demanding evil would involve. He casts the disposition to act with more robust maleficence as a disposition that operates on an agent in the same manner as a disposition to act with more beneficence would operate. And he argues that as we take the mundanely beneficent disposition to restrict your deliberation, thereby reducing my vulnerability to your will, so we should think of your mundanely maleficent disposition as having a similar effect.

I disagree with Taylor's main claim here but I think that he has pinpointed a lacuna in my discussion of maleficence, robust and mundane. More robust beneficence of the mundane variety is continuous with fully robust beneficence, approximating the threshold for the fully robust variety. But more robust maleficence of the mundane variety is not continuous with heroic maleficence. Mundane maleficence becomes more robust as fewer constraints are allowed to restrict your self-interest. But heroic maleficence does not consist in acting purely out of self-interest, with few or no constraints; it does not kick in that or any other level of robustness. What it involves is something quite different: that selfinterest drops out in favor of a will to do harm for harm's sake. It is because it has that downright fiendish character that I now doubt its very coherence.

Taylor argues that as dispositions to do robust good should constrain your deliberation and will, so dispositions to do robust evil should be expected to have the same effect. But if the argument is sound, it applies at most in the case of heroic maleficence. It suggests that insofar as you are heroically maleficent-a sworn enemy, as it were, for whom your only good is evil for me-I can at least know where I stand: your will is fixed and I am not at the mercy of the different ways it might go.

I say that the argument applies at most with heroic maleficence, since I have doubts even in this case. A robust disposition to do good constrains you by 
sensitizing you to standards of good, where such sensitivity is consistent with your being a deliberative agent with a free will. But a robust disposition to do evil, of the kind imagined here, cannot constrain you in that way. And when we think about how it might constrain you, the most obvious suggestion is that it operates like a pathology, driving you or pre-programing you, in words that Taylor himself uses. If it operates in that way, of course, then you do not really have a free will. And to the extent that you lack free will-to the extent that you are some variety of psychopath-you do not represent the sort of danger on which I focus: like a force of nature, you become a non-voluntary source of harm.

Taylor is focused, however, on the case of mundane rather than heroic maleficence and we should return to it. Mundane maleficence becomes more robust insofar as more and more self-serving concerns are allowed to prompt the denial of a benefit and the imposition of a cost. Thus, breaking a promise is more robustly maleficent when you break it because it is 'a little inconvenient for you to keep it', less robust when you break it only because it is 'seriously troublesome to keep it' (RDG, p. 175).

It should be clear that as maleficence becomes more robust in this case, I am exposed more and more to your will: I am at the mercy of a greater and greater number of considerations that you might valorize to my detriment. Thus, there is no reason to reject the more-robust-is-worse principle. Taylor identifies a weakness in the idea that if you are heroically evil, I am especially vulnerable to your will and that that is one reason why heroic evil is so bad. But the argument he invokes does not apply in the mundane case he addresses.

The bulk of Taylor's paper is given to my argument that principles like the doctrine of double effect can be seen as moral heuristics that may be generally helpful in guiding us but often fail to support positions they are invoked to defend. While broadly agreeing that they have this status, he criticizes my argument for that conclusion and offers a very interesting argument instead.

I hold that the principles at issue here will be helpful insofar as they reflect implications of the more-robust-is-worse principle and that they will not be of value otherwise. The idea, in the case of the doctrine of double effect, is that acting on an intention to harm someone is generally going to involve imposing a cost more robustly than foreseeing, perhaps with regret, that something you intend to do will impose that cost. And a similar sort of idea applies in two other cases, so I maintain, one involving the act-omission principle, the other a principle comparing remedying an evil and acting to prevent it.

In the case of the act-omission principle, the idea in parallel is that positively harming someone as distinct from failing to prevent harm is going to involve imposing the harm more robustly, as there may be others who will 
prevent the harm you yourself fail to prevent. And in the case of remedy versus prevention-saving trapped miners as distinct from acting to prevent mine collapses-the idea is that there are going to be identified individuals whom you can robustly harm by any failure to remedy the situation where this is not always true with prevention. Thus, if other things are equal-a condition not often satisfied, since prevention will usually tend to help more individualsremedy will be more appealing than prevention.

Taylor argues that the cases where following the doctrine of double effect or the act-omission principle come apart are likely to be more numerous than I suggest, so that they will not be particularly useful heuristics. And he also argues against my claim that we should always rank remedy over prevention when other things are equal. He points out, plausibly, that there are cases where a failure to prevent, such as a failure to guard against the collapse of a mine with identifiable miners, may harm people just as robustly as a failure to remedy.

I do not think that the divide between Taylor and me on these points is of great moment. It may be that the doctrine of double effect and the act-omission principle are not useful as moral heuristics to the extent that I suggest. I would be happy so long as they are useful enough in this role to explain their appeal, without implying that they represent independent moral constraints. And I would be equally happy to concede the point that he makes about the remedy-prevention principle, for it does not affect the main line of argument.

Taylor makes a very interesting contribution in the final part of his paper, where he offers a distinct line of argument in favor of granting the status of defeasible moral heuristics to the three principles discussed. I welcome this, even while continuing to think that the more-robust-is-worse principle stands and that it also supports granting a heuristic status to the principles. There is no reason why this ascription of status should not be supported on more than one ground.

Taylor's argument begins from the observation that with any norm against harm that we may expect to obtain in any society, there are two distinct ways in which you can do bad by violating it. Most obviously, you will do bad insofar as breaching the norm involves harming your victim. But if your breach of that norm is recognized by others-perhaps recognized by all as a matter of common awareness-whether at the time of action or later, then it may serve as a signal to others that conformity is not standard and need not attract severe sanction, at least in the economy of esteem. In terms introduced by Robert Nozick, it means that the breach not only has substantive disutility in harming another, it also has symbolic disutility in giving off a signal that may contribute, however imperceptibly, to undermining the norm. 
Taylor points out that the three principles under discussion may be very useful moral heuristics insofar as the actions they more heavily censure have greater symbolic disutility than the actions they censure less severely. It sends a worse message to act with the intention of harming someone as distinct from acting in a way that, as you foresee, will cause harm; to harm someone directly as distinct from failing to prevent a harm; and not to remedy the situation of someone in difficulty as distinct from failing to prevent that type of difficulty arising in the first place. I find this claim plausible and congenial but view it as a complement to my own argument, not as a replacement. ${ }^{6}$

\section{References}

Ferguson, B. (2018). 'The Value of Robustness: Promotion or Protection', Moral Philosophy and Politics 5 (1): 9-27.

Gädeke, D. (2018). 'The Robust Demands of the Right', Moral Philosophy and Politics 5 (1): 29-47.

Gregoratto, F. (2018). 'The Robust Demands of Oppression: Problematizing Pettit's Account of Attachments', Moral Philosophy and Politics 5 (1): 49-67.

Nyholm, S. (2018). 'Pettit on Love and its Value: A Critical Assessment', Moral Philosophy and Politics 5 (1): 87-102.

Pettit, P. (2001). A Theory of Freedom: From the Psychology to the Politics of Agency (London: Polity Press).

Pettit, P. (2014). Just Freedom: A Moral Compass for a Complex World (New York: W.W. Norton). Pettit, P. (2015). The Robust Demands of the Good: Ethics with Attachment, Virtue and Respect (Oxford: Oxford University Press).

Pettit, P. (2018a). The Birth of Ethics (Oxford: Oxford University Press).

Pettit, P. (2018b). 'Three Mistakes about Doing Good (and Bad)', Journal of Applied Philosophy 35 , online first.

Taylor, I. (2018). 'Robust Harms', Moral Philosophy and Politics 5 (1): 69-85.

6 The symposium on The Robust Demands of the Good draws in good part on two 2016 workshops on the book, one in Berlin at the Freie Universität, the other at the University of St. Gallen. I am most grateful to the organizers and contributors to both of those events. I am particularly grateful to Susanne Burri for her comments and suggestions in response to an earlier draft; she helped me to see some significant points I had overlooked. 